\title{
Hydraulic modelling of drip irrigation systems used for grass establishment on steep slopes
}

\author{
Y. Gyasi-Agyei \\ Centre for Railway Engineering, Central Queensland University, \\ Australia
}

\begin{abstract}
Erosion damage to railway embankment and cutting steep slopes (batters) causes a significant cost of remediation within the coal railway network of Central Queensland, Australia. It has been established that grass cover of $60 \%$ reduces erosion by over $90 \%$. Given that water is a scarce commodity in the semi-arid environment, a more efficient water use cost-effective drip irrigation system is imperative. The hydraulic modelling of drip irrigation systems design is presented. It takes into account the velocity head change and a proper selection of the friction coefficient formula based on the Reynolds number. Fittings and emitter insertion head loss are incorporated into the hydraulic model. A case study of the use of the hydraulic model to analyse the drip irrigation systems is presented.

Keywords: steep slopes, drip lateral, irrigation, hydraulics, embankment, grass establishment.
\end{abstract}

\section{Introduction}

Erosion of railway embankment and cutting batters within Central Queensland, Australia, increases maintenance costs, risks of outages and derailments, interruptions of normal train operations and environmental degradation. The QR (Queensland Rail) funded HEFRAIL Research Project with Central Queensland University has demonstrated that $60 \%$ grass cover on railway embankment batters reduces erosion by over $90 \%$ compared with the bare scenario. Further increase in grass cover increases the erosion reduction up to $99 \%$ [1-3]. Drip irrigation systems, consisting of laterals with equally spaced emitters and uniform slope, have been identified as an integral part of grass establishment to 
control erosion on railway embankment steep slopes (batters) within the semiarid region [2, 4-6]. Water is a scarce commodity and may be sourced from existing water mains, existing or temporary excavated ponds/ dams/ creek water holes, or temporary tanks filled periodically by water trucks. The choice of water source depends on availability and costs.

There have been several studies of the hydraulics of drip laterals [e.g. 7]. Yildirim and Agiralioglu [8] have reviewed and compared the performance of some approaches for solving the hydraulics of drip laterals. Basic differences in the approaches are essentially the inclusion or not of the velocity head and minor losses due to emitter insertion, and the treatment of the emitter discharges as constant or variable along the lateral. However, the forward-step method proposed by Hathoot et al [9] has been described by many authors [e.g. 10, 11] as the most accurate method. This method takes into account the velocity head change and a proper selection of the friction coefficient formula based on the Reynolds number which varies along the lateral. Recent studies have shown that emitter insertion head loss contributes to a significant proportion of the total head losses, in particular where the emitter numbers are high within the lateral, and needs to be taken into account [11-13].

Field values of emitter characteristics may be significantly different from the manufacturer supplied values as a result of manufacturing variations, microtopography, clogging, and water quality [12, 14]. Gyasi-Agyei [14] has presented a novel approach for field scale assessment of the uncertainties associated with the drip lateral parameters. This paper gives an example of the use of the hydraulic model presented in Gyasi-Agyei [14] to simulate drip lateral designs at multiple sites of a new railway spur line.

\section{The hydraulic model}

\subsection{Single Lateral}

Emitter discharge varies along the lateral with maximum value at upstream and zero at the end. Consider the lateral in fig. 1 having inlet pressure head $\mathrm{H}_{0}$ and discharge $\mathrm{Q}_{0}$, and equal emitter spacing s. It is more convenient to cut the lateral midway between two emitters at the connection point to the submain. Hence the head loss in this small section needs to be taken into account when estimating the pressure head at the first emitter. The discharge $\mathrm{q}_{i}\left(\mathrm{~L} \cdot \mathrm{h}^{-1}\right)$ from an emitter $\mathrm{i}$ is determined by the rating curve

$$
q_{i}=k H_{i}^{x}
$$

where $H_{i}(m)$ is the pressure head in the lateral at the emitter $i, x$ is the emitter discharge exponent characterizing the flow regime and emitter type, and $\mathrm{k}$ is emitter discharge coefficient.

The Forward-Step Method equation [14]

$$
H_{i+1}=H_{i}+\frac{3}{2 g A^{2}}\left[Q_{i}^{2}-Q_{i+1}^{2}\right]-\left[\frac{8 s}{\pi^{2} g D^{5}} f_{i+1}+\frac{\alpha}{2 g A^{2}}\right] Q_{i+1}^{2}-s s_{O}
$$


is used to solve for the emitter pressure and discharges forwards. In eqn. (2) $\mathrm{s}_{\mathrm{o}}=\left(\mathrm{z}_{\mathrm{i}+1}-\mathrm{Z}_{\mathrm{i}}\right) / \mathrm{L}$ is the constant slope of the lateral (positive for uphill and negative for downhill), $\mathrm{D}(\mathrm{m})$ is diameter, $\mathrm{A}\left(\mathrm{m}^{2}\right)$ is cross-sectional area, $\mathrm{H}_{\mathrm{i}}(\mathrm{m})$ is the pressure head at emitter i, $Q_{i}(m)$ is discharge flowing to emitter $i, s(m)$ is emitter spacing, and $L(m)$ is the length of the lateral. The friction coefficient $f_{i+1}$ is defined by

$$
\begin{gathered}
f_{i+1}=\frac{64}{R_{i+1}}, \quad R_{i+1} \leq 2000 \quad \text { laminar flow } \\
f_{i+1}=\frac{0.316}{R_{i+1}^{0.25}}, \quad 3000<R_{i+1} \leq 10^{5} \quad \text { turbulent flow } \\
f_{i+1}=\frac{0.130}{R_{i+1}^{0.172}}, \quad 10^{5}<R_{i+1}<10^{7} \quad \text { fully turbulent flow }
\end{gathered}
$$

where $\mathrm{R}_{\mathrm{i}+1}$ is the Reynolds number. Eqn. (2) was proposed by Hathoot et al [9] except for the addition of the local head loss term due to emitter insertions estimated as kinetic head multiplied by the emitter head loss coefficient $\alpha$.

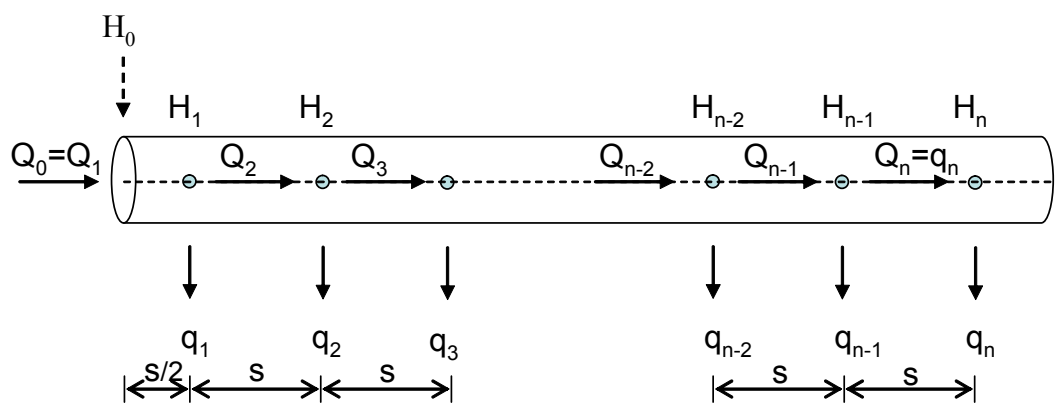

Figure 1: $\quad$ Single drip lateral hydraulic features.

For a given lateral inlet pressure $\mathrm{H}_{0}$ the emitter discharges are obtained by solving eqn. (2) forwards. Initially the inlet discharge $\mathrm{Q}_{0}=\mathrm{Q}_{1}$ is assumed and used with eqn. (3) to evaluate the friction coefficient $f_{1}$. With eqn. (2) $H_{1}$ is calculated, followed by the calculation of $\mathrm{q}_{1}$ using eqn. (1), and then calculation of $\mathrm{Q}_{2}$ which equals $\mathrm{Q}_{1}-\mathrm{q}_{1}$. The calculation is repeated for the next emitter downstream until the last emitter discharge $\mathrm{q}_{\mathrm{n}}$ is estimated. For a given lateral's characteristic parameters and inlet pressure, there is a unique solution of $\mathrm{Q}_{0}$ such that

$$
\mathrm{Q}_{0}-\sum_{\mathrm{i}=1}^{\mathrm{n}} \mathrm{q}_{\mathrm{i}}=0, \quad \mathrm{Q}_{\mathrm{n}}=\mathrm{q}_{\mathrm{n}}>0
$$

In other words, it is a problem of finding the root $\left(\mathrm{Q}_{0}\right)$ of a non-linear function of eqn. (4). The greater than zero condition is important since below a threshold value of $\mathrm{Q}_{0}$ for a fixed inlet pressure there is no flow through the last emitter. Any root finding algorithm can be used to solve eqn. (4). Brent root finding algorithm, which combines root bracketing, interval bisection, linear 
interpolation and inverse quadratic interpolation, is used with the lower and upper values of $\mathrm{Q}_{0}$ defined by $0.1 n k H_{0}^{x}<Q_{0}<n k H_{0}^{x}$ to solve eqn. (4).
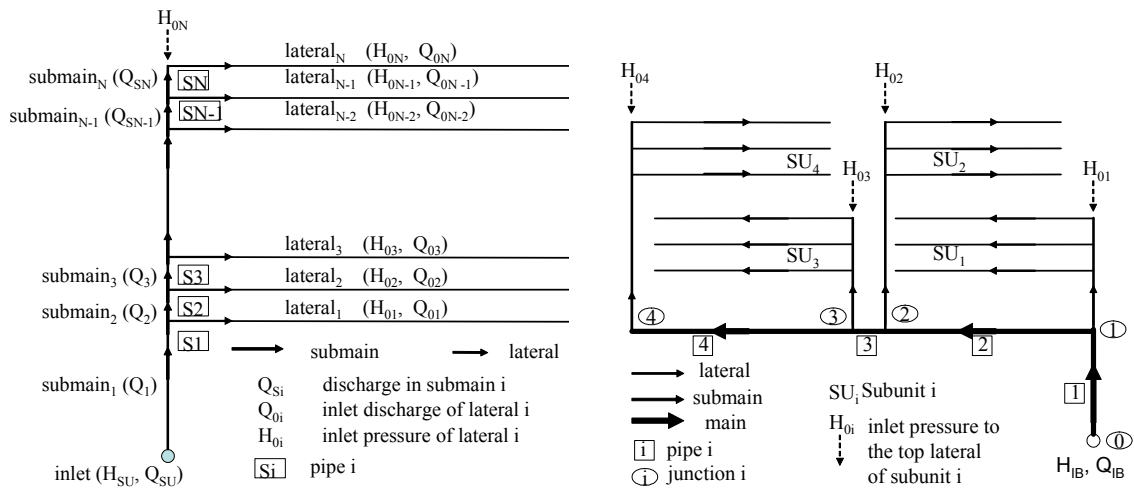

Figure 2: An irrigation subunit (left) and an irrigation bay with multiple subunits (right).

Similar concepts used for a single lateral are used for the subunit simulation as depicted in fig. 2 (left). The subunit inlet discharge $\mathrm{Q}_{\mathrm{SU}}$ is a unique function of the top lateral inlet pressure $\mathrm{H}_{0 \mathrm{i}}$. Given $\mathrm{H}_{0 \mathrm{~N}}, \mathrm{Q}_{0 \mathrm{~N}}$ is estimated as explained for the single lateral case. Since $\mathrm{Q}_{0}$ is the same as the discharge through the top submain, $\mathrm{H}_{0 \mathrm{~N}-1}$ is estimated using the Backward-Step energy formula

$$
H_{0 i-1}=H_{0 i}+f_{S i} \frac{8 L_{S i}}{\pi^{2} g D_{S i}^{5}} Q_{S i}^{2}+L_{S i} s_{O}+k_{e S i} \frac{Q_{S i}^{2}}{2 g A_{S i}^{2}}
$$

where $\mathrm{L}_{\mathrm{Si}}$ is the length of submain pipe $\mathrm{Si}$ between the laterals. The last term represents changes in geometry and fittings head loss with $\mathrm{k}_{\mathrm{eSi}}$ the total upstream coefficient for pipe $\mathrm{Si}$. The remaining symbols are as previously defined. Knowing $\mathrm{H}_{0 \mathrm{~N}-1}, \mathrm{Q}_{0 \mathrm{~N}-1}$ can be estimated and added to $\mathrm{Q}_{0 \mathrm{~N}}$ to give the discharge in the submain $\mathrm{SN}-1, \mathrm{Q}_{\mathrm{SN}-1}$. The process is repeated for the next lateral and submain backwards until the subunit inlet pressure $\mathrm{H}_{\mathrm{SU}}$ and discharge $\mathrm{Q}_{\mathrm{SU}}$ are estimated. Hence pressure $\mathrm{H}_{0 \mathrm{~N}}$ can be optimised to match the given $\mathrm{Q}_{\mathrm{SU}}$ and simulated $\mathrm{Q}^{*} \mathrm{SU}$ subunit inlet discharges. Hence it is a problem of finding the root $\left(\mathrm{H}_{0 \mathrm{~N}}\right)$ of a non-linear equation formulated as

$$
\text { QSU - } \mathrm{Q}_{S U}^{*}\left(\mathrm{H}_{0 \mathrm{~N}}\right)=0
$$

satisfying the conditions given in the single lateral case. Eqn. (6) is solved using a modified Powell's hybrid algorithm which is a variation of Newton's method using a finite-difference approximation to the Jacobian.

To illustrate the principles for multiple subunits consider fig. 2 (right) which consists of four subunits joined to the main pipeline to form a single irrigation bay. Each subunit requires only the inlet pressure $\left(\mathrm{H}_{0 \mathrm{i}}\right)$ of the top lateral to estimate the pressure and discharge at the inlet of the subunit as described in the preceding paragraph. From hydraulic principles, pipes flowing away from a 
junction should have the same upstream pressure equal to the downstream pressure of the pipe flowing into the junction. To satisfy the continuity principle, the total flow into a junction must equal the total flow out of the junction. Therefore the problem can be formulated into a system of $M$ (equal to the number of subunits) non-linear equations with $\mathrm{M}$ unknowns (the inlet pressures of the top laterals of the M subunits). Hence

$$
\begin{array}{ll}
\text { at junction 0: } & \mathrm{Q}_{\mathrm{IB}}-\mathrm{Q}_{\mathrm{p} 1}\left(\mathrm{H}_{01}, \mathrm{H}_{02}, \mathrm{H}_{03}, \mathrm{H}_{04}\right)=0 \\
\text { at junction 1: } & \mathrm{H}_{0 \mathrm{SU} 1}\left(\mathrm{H}_{01}\right)-\mathrm{H}_{\mathrm{p} 2 \mathrm{up}}\left(\mathrm{H}_{02}, \mathrm{H}_{03}, \mathrm{H}_{04}\right)=0 \\
\text { at junction 2: } & \mathrm{H}_{0 \mathrm{SU} 2}\left(\mathrm{H}_{02}\right)-\mathrm{H}_{\mathrm{p} 3 \mathrm{up}}\left(\mathrm{H}_{03}, \mathrm{H}_{04}\right)=0 \\
\text { at junction 3: } & \mathrm{H}_{0 \mathrm{SU} 3}\left(\mathrm{H}_{03}\right)-\mathrm{H}_{\mathrm{p} 4 \mathrm{up}}\left(\mathrm{H}_{04}\right)=0
\end{array}
$$

where $\mathrm{H}_{\text {piup }}$ is the upstream pressure of main pipe i, $\mathrm{H}_{0 \mathrm{i}}$ is the inlet pressure of the top lateral of subunit $i$, and $\mathrm{H}_{0 \mathrm{SUi}}$ is the inlet pressure of subunit $\mathrm{i}, \mathrm{Q}_{\mathrm{pi}}$ and $\mathrm{Q}_{\mathrm{IB}}$ are the discharges in pipe $i$ and the total of the irrigation bay, respectively. Again the conditions given in the single lateral case must be satisfied. The system of nonlinear equations is solved by the same procedure used for the single subunit case.

\section{Case study: site 7 embankment of Bauhinia Regional Rail Project}

\subsection{Site description}

Bauhinia Regional Rail Project (BRRP) is the construction of a $110 \mathrm{~km}$ spur line linking the new Rolleston Coal Mine to the Blackwater rail network at Kinrola in Central Queensland, Australia [6]. Big cuttings and embankments, and bridges and culverts, are major construction activities as a result of the route crossing various terrains from rocky mountainous country in the north to expansive black soil river plains in the south. In order to reduce the treatment costs, only the top $3 \mathrm{~m}$ of batters of all embankment sections exceeding $4 \mathrm{~m}$ in height and the downstream side embankment batters of the two major flood plains were irrigated. Three rows of driplines $(17.6 \mathrm{~mm}$ internal diameter, $0.3 \mathrm{~m}$ emitter spacing, and $2.5 \mathrm{~L} / \mathrm{h}$ nominal emitter discharge) at $1 \mathrm{~m}$ row spacing were set up at the top batter sections of the selected embankments. Field scale assessment of the selected dripline characteristics [14] has indicated the effective parameter values are: $\mathrm{x}=0.493, \mathrm{k}=0.71$ and $\alpha=0.252$ which is significantly different from the manufacturer's supplied values of $\mathrm{x}=0.55, \mathrm{k}=0.68$ and $\alpha=0.15$. The variations in the dripline parameter values are attributed to manufacturing variations of the emitters, as well as environmental factors and water quality. Site 7 , with a maximum height of $11.6 \mathrm{~m}$, is located between $12880 \mathrm{~m}$ and $13480 \mathrm{~m}$ marks. Fig. 3 shows the layout of the irrigation system and the line drawings of the pipes of the eastern side, noting that the western side line drawings are the same as the eastern except for length of pipe 57. 

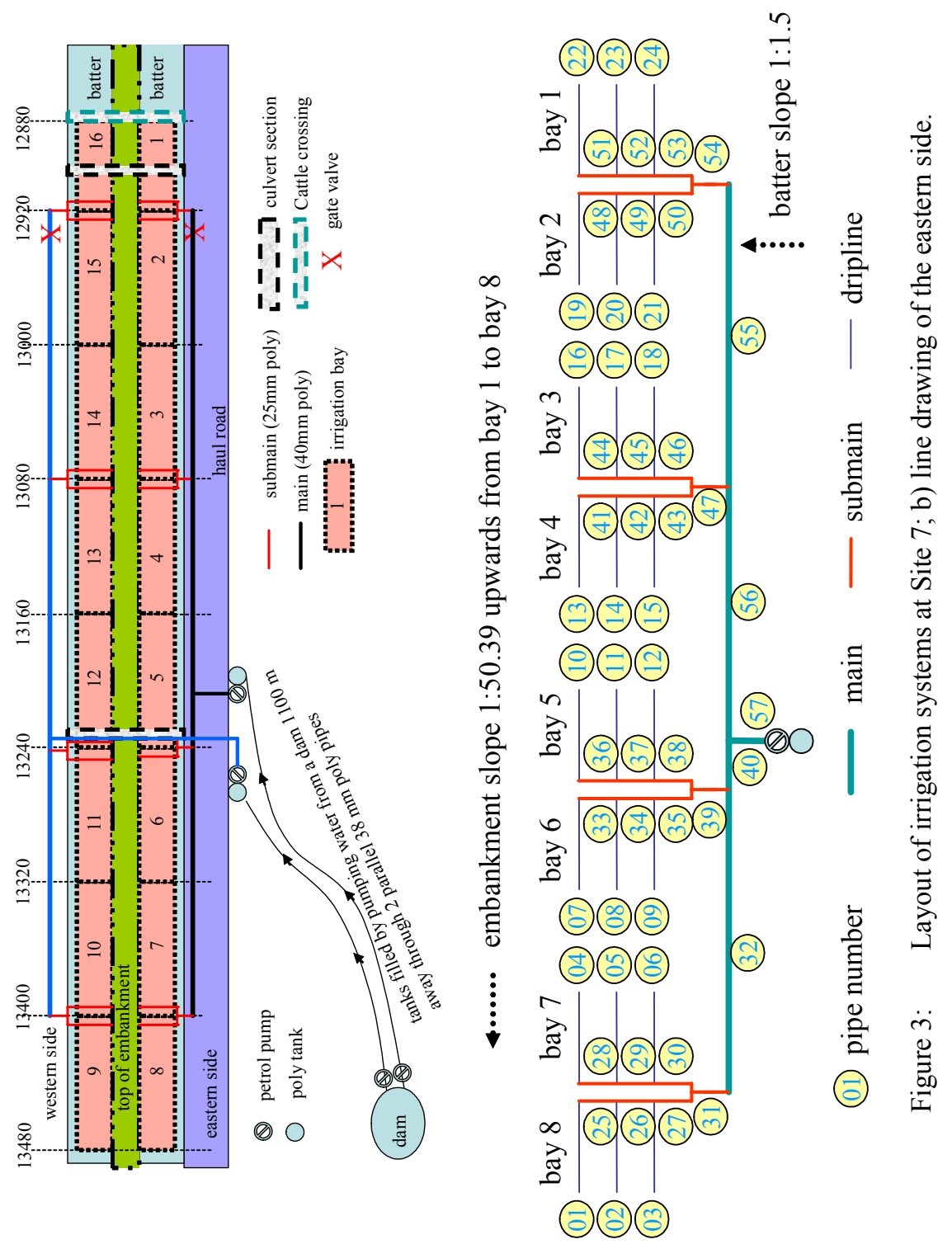


\subsection{Hydraulic simulation of eastern side}

Table 1 provides the pipe characteristics used in the modelling. Initial experiments at some selected sites of the BRRP project established that to achieve a good uniform wetting front the driplines should not exceed $80 \mathrm{~m}$. A gate valve was installed in the mains to bays $1,2,15$ and 16 to reduce the higher emitter discharges due to the high elevation drop. The opening area of the gate valves is judged by visual inspections of the wetting fronts. However, the local head loss coefficient ke due to the gate valve is estimated as the value to give similar emitter discharges as for bays 1 and 8 .

Fig. 4 depicts the irrigation system curve superimposed on the pump performance curve. ke value of 100 for the gate valve yielded a similar emitter discharges for bays 1 and 8 . This implies the gate valve will be nearly shut. For the given conditions, the pump operating point is about $240 \mathrm{~L} / \mathrm{min}$ at $32 \mathrm{~m}$ head. Table 2 gives the characteristics of the 24 driplines at this pump operating point. It is observed that the coefficient of variation (standard deviation/ mean) of the emitters of all bays is small, the maximum being less than $6 \%$.

Water was pumped from a dam $1100 \mathrm{~m}$ away through two parallel $38 \mathrm{~mm}$ poly pipes to $25,000 \mathrm{~L}$ tanks located at the bottom of the embankment as shown in Fig. 3. The measured flow rate through each supply pipe, with independent pump, was about $60 \mathrm{~L} / \mathrm{min}$. Hence for one hour irrigation, each pump on the dam has to run for 4 hours $(240 / 60)$. Due to the expected increase in frictional head losses and emitter clogging by fine sediments in the irrigation water, this factor may be reduced. To minimise this risk, the driplines are flushed on a continuous basis. The hydraulic simulation is therefore a valuable tool to make a prior judgement of costs associated with the drip irrigation.

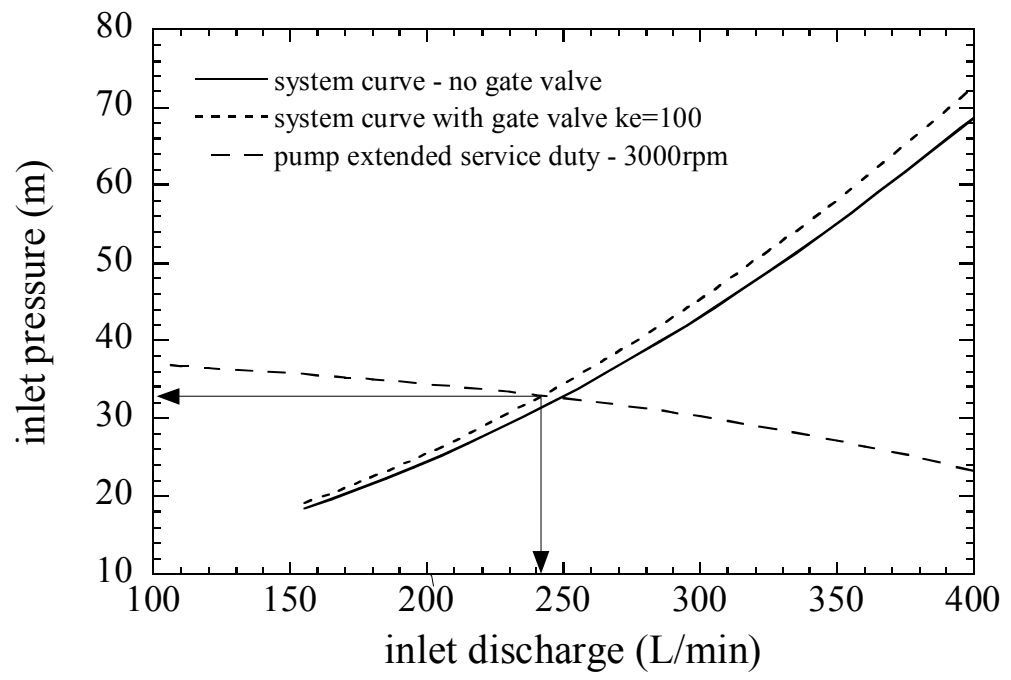

Figure 4: Pump characteristics and system curves. 
Table 1: $\quad$ Pipe characteristics used in the simulation.

\begin{tabular}{|c|c|c|c|c|c|c|c|c|c|c|c|c|c|c|}
\hline 1 & \begin{tabular}{l|l}
2 & 3 \\
\end{tabular} & 4 & 5 & 6 & 7 & 8 & 1 & 2 & 3 & 4 & 5 & 6 & 7 & 8 \\
\hline 1 & 125 & 1 & 80.00 & 247.289 & 248.877 & 1.08 & 30 & 2 & 31 & 30 & 16.00 & 238.566 & 247.289 & 2.70 \\
\hline 2 & 126 & 2 & 80.00 & 245.289 & 246.877 & 1.98 & 31 & 23 & 32 & 31 & 0.01 & 238.566 & 238.566 & 0.18 \\
\hline 3 & 127 & 3 & 80.00 & 243.289 & 244.877 & 1.98 & 32 & 34 & 40 & 32 & 163.00 & 233.768 & 238.566 & 0.60 \\
\hline 4 & 128 & 4 & 80.00 & 247.289 & 245.702 & 1.08 & 33 & 23 & 34 & 33 & 1.00 & 244.114 & 244.114 & 0.60 \\
\hline 5 & 129 & 5 & 80.00 & 245.289 & 243.702 & 1.98 & 34 & 23 & 35 & 34 & 1.00 & 244.114 & 244.114 & 0.60 \\
\hline 6 & 130 & 6 & 80.00 & 243.289 & 241.702 & 1.98 & 35 & 23 & 39 & 35 & 19.00 & 233.768 & 244.114 & 2.70 \\
\hline 7 & 133 & 7 & 80.00 & 244.114 & 245.702 & 1.08 & 36 & 23 & 37 & 36 & 1.00 & 244.114 & 244.114 & 0.60 \\
\hline 8 & 134 & 8 & 80.00 & 242.114 & 243.702 & 1.98 & 37 & 23 & 38 & 37 & 1.00 & 244.114 & 244.114 & 0.60 \\
\hline 9 & 135 & 9 & 80.00 & 240.114 & 241.702 & 1.98 & 38 & 23 & 39 & 38 & 19.00 & 233.768 & 244.114 & 2.70 \\
\hline 10 & 136 & 10 & 80.00 & 244.114 & 242.527 & 1.08 & 39 & 24 & 40 & 39 & 0.01 & 233.768 & 233.768 & 2.11 \\
\hline 11 & 137 & 11 & 80.00 & 242.114 & 240.527 & 1.98 & 40 & 35 & 57 & 40 & 21.00 & 234.300 & 233.768 & 1.80 \\
\hline 12 & 138 & 12 & 80.00 & 240.114 & 238.527 & 1.98 & 41 & 24 & 42 & 41 & 1.00 & 240.939 & 240.939 & 0.60 \\
\hline 13 & \begin{tabular}{l|l}
1 & 41 \\
\end{tabular} & 13 & 80.00 & 240.939 & 242.527 & 1.08 & 42 & 24 & 43 & 42 & 1.00 & 240.939 & 240.939 & 0.60 \\
\hline 14 & $\begin{array}{ll}142 \\
\end{array}$ & 14 & 80.00 & 238.939 & 240.527 & 1.98 & 43 & 24 & 47 & 43 & 16.00 & 234.636 & 240.939 & 2.70 \\
\hline 15 & 143 & 15 & 80.00 & 236.939 & 238.527 & 1.98 & 44 & 24 & 45 & 44 & 1.00 & 240.939 & 240.939 & 0.60 \\
\hline 16 & 144 & 16 & 80.00 & 240.939 & 239.351 & 1.08 & 45 & 24 & 46 & 45 & 1.00 & 240.939 & 240.939 & 0.60 \\
\hline 17 & 145 & 17 & 80.00 & 238.939 & 237.351 & 1.98 & 46 & 24 & 47 & 46 & 16.00 & 234.636 & 240.939 & 2.70 \\
\hline 18 & 146 & 18 & 80.00 & 236.939 & 235.351 & 1.98 & 47 & 25 & 56 & 47 & 0.01 & 234.636 & 234.636 & 2.11 \\
\hline 19 & 148 & 19 & 80.00 & 237.764 & 239.351 & 1.08 & 48 & 24 & 49 & 48 & 1.00 & 237.764 & 237.764 & 0.60 \\
\hline 20 & 149 & 20 & 80.00 & 235.764 & 237.351 & 1.98 & 49 & 25 & 50 & 49 & 1.00 & 237.764 & 237.764 & 0.60 \\
\hline 21 & \begin{tabular}{l|l}
150 \\
\end{tabular} & 21 & 80.00 & 233.764 & 235.351 & 1.98 & 50 & 25 & 54 & 50 & 15.00 & 232.736 & 237.764 & 2.70 \\
\hline 22 & \begin{tabular}{l|l}
1 & 51 \\
\end{tabular} & 22 & 40.00 & 237.764 & 236.970 & 1.08 & 51 & 25 & 52 & 51 & 1.00 & 237.764 & 237.764 & 0.60 \\
\hline 23 & 152 & 23 & 40.00 & 235.764 & 234.970 & 1.98 & 52 & 25 & 53 & 52 & 1.00 & 237.764 & 237.764 & 0.60 \\
\hline 24 & 153 & 24 & 40.00 & 233.764 & 232.970 & 1.98 & 53 & 25 & 54 & 53 & 15.00 & 232.736 & 237.764 & 2.70 \\
\hline 25 & \begin{tabular}{|l|l|}
2 & 26 \\
\end{tabular} & 25 & 1.00 & 245.289 & 247.289 & 0.60 & 54 & 25 & 55 & 54 & 0.01 & 232.736 & 232.736 & 100.18 \\
\hline 26 & 227 & 26 & 1.00 & 243.289 & 245.289 & 0.60 & 55 & 35 & 56 & 55 & 163.00 & 234.636 & 232.736 & 0.60 \\
\hline 27 & $\begin{array}{ll}2 & 31 \\
\end{array}$ & 27 & 16.00 & 238.566 & 243.289 & 2.70 & 56 & 35 & 57 & 56 & 141.00 & 234.300 & 234.636 & 1.80 \\
\hline 28 & 229 & 28 & 1.00 & 245.289 & 247.289 & 0.60 & 57 & 35 & 58 & 57 & 3.00 & 234.300 & 234.300 & 0.00 \\
\hline 29 & 230 & 29 & 1.00 & 243.289 & 245.289 & 0.60 & & & & & & & & \\
\hline
\end{tabular}

\section{Column headings}

1) pipe number; 2) pipe type 1 for dripline, 2 for $25 \mathrm{~mm}$ submain, 3 for $38 \mathrm{~mm}$ mains; 3) upstream connected node; 4) downstream connected node; 5) length (m); 6) upstream elevation (m); 7) downstream elevation $(\mathrm{m})$; 8) upstream connection friction loss coefficient, ke.

NB: additional $\mathrm{ke}=100$ for pipe 54 is due to gate valve. 
Table 2: Dripline characteristics at the pump operating point $(240 \mathrm{~L} / \mathrm{min}$, $32 \mathrm{~m})$.

\begin{tabular}{|c|c|c|c|c|c|c|c|c|}
\hline 1 & 2 & 3 & 4 & 5 & 6 & 7 & 8 & 9 \\
\hline 1 & 9.51 & 1.51 & 0.46 & 0.023 & 11.32 & 2.14 & 9.40 & 4.42 \\
\hline 2 & 9.75 & 1.58 & 0.49 & 0.045 & 11.88 & 2.20 & 9.89 & 4.29 \\
\hline 3 & 10.00 & 1.66 & 0.52 & 0.047 & 12.47 & 2.26 & 10.42 & 4.17 \\
\hline 4 & 10.14 & 1.76 & 0.55 & 0.027 & 11.21 & 2.29 & 10.71 & 0.86 \\
\hline 5 & 10.37 & 1.83 & 0.57 & 0.051 & 11.77 & 2.34 & 11.20 & 0.86 \\
\hline 6 & 10.61 & 1.91 & 0.60 & 0.053 & 12.37 & 2.39 & 11.74 & 0.86 \\
\hline 7 & 11.88 & 2.29 & 0.73 & 0.036 & 17.24 & 2.68 & 14.76 & 3.51 \\
\hline 8 & 12.07 & 2.36 & 0.75 & 0.069 & 17.81 & 2.72 & 15.25 & 3.45 \\
\hline 9 & 12.28 & 2.43 & 0.78 & 0.071 & 18.41 & 2.77 & 15.80 & 3.40 \\
\hline 10 & 12.38 & 2.53 & 0.81 & 0.040 & 17.12 & 2.79 & 16.07 & 0.99 \\
\hline 11 & 12.57 & 2.60 & 0.84 & 0.075 & 17.69 & 2.83 & 16.55 & 1.00 \\
\hline 12 & 12.77 & 2.68 & 0.87 & 0.077 & 18.30 & 2.88 & 17.11 & 1.02 \\
\hline 13 & 10.66 & 1.87 & 0.59 & 0.029 & 14.03 & 2.40 & 11.85 & 3.90 \\
\hline 14 & 10.87 & 1.94 & 0.61 & 0.056 & 14.59 & 2.45 & 12.34 & 3.82 \\
\hline 15 & 11.11 & 2.02 & 0.64 & 0.058 & 15.19 & 2.51 & 12.88 & 3.74 \\
\hline 16 & 11.23 & 2.12 & 0.67 & 0.033 & 13.92 & 2.53 & 13.17 & 0.89 \\
\hline 17 & 11.43 & 2.19 & 0.70 & 0.062 & 14.49 & 2.58 & 13.66 & 0.90 \\
\hline 18 & 11.65 & 2.26 & 0.72 & 0.064 & 15.09 & 2.63 & 14.20 & 0.92 \\
\hline 19 & 7.90 & 1.06 & 0.32 & 0.016 & 8.05 & 1.78 & 6.46 & 5.52 \\
\hline 20 & 8.19 & 1.14 & 0.34 & 0.032 & 8.61 & 1.85 & 6.95 & 5.28 \\
\hline 21 & 8.49 & 1.22 & 0.37 & 0.034 & 9.19 & 1.91 & 7.47 & 5.05 \\
\hline 22 & 4.58 & 0.19 & 0.05 & 0.005 & 8.45 & 2.06 & 8.71 & 1.05 \\
\hline 23 & 4.72 & 0.20 & 0.06 & 0.011 & 9.01 & 2.13 & 9.25 & 0.97 \\
\hline 24 & 4.85 & 0.22 & 0.06 & 0.011 & 9.57 & 2.19 & 9.80 & 0.90 \\
\hline
\end{tabular}

\section{Column headings}

1) total discharge (L/min); 2) total friction loss $(\mathrm{m})$; 3) friction loss due to emitter insertion $(\mathrm{m})$; 4) friction loss due to dripline connections $(\mathrm{m}) ; 5)$ dripline upstream pressure $(\mathrm{m}) ; 6$ ) average emitter discharge (L/min); 7) average emitter pressure $(\mathrm{m})$; 8) emitter discharge coefficient of variation (standard deviation / mean) (\%).

\section{Conclusions}

Drip irrigation systems are being routinely used to aid the establishment of grasses on railway embankment steep slopes to control erosion within the semi-arid region of Central Queensland, Australia. The hydraulic modelling approach used to aid the design of the drip irrigation systems has been presented in this paper. It takes into account the velocity head change and a proper selection of the friction coefficient formula based on the Reynolds number. Fittings and emitter insertion head loss are incorporated into the hydraulic 
model. The hydraulic model was use to design drip irrigation systems at 37 sites on the recently constructed BRRP spur railway line. One of the sites has been used as a case study in this paper. The hydraulic simulation has been found to be a valuable tool to make a prior judgement of costs associated with the drip irrigation system.

\section{Acknowledgement}

This research is part of HEFRAIL Project which is fully funded by Queensland Rail (QR), and this support is gratefully acknowledged.

\section{References}

[1] Gyasi-Agyei, Y., Sibley, J. \& Ashwath, N., Quantitative evaluation of strategies for erosion control on a railway embankment batter. Hydrolog. Process., 15, pp. 3249-3268, 2001.

[2] Gyasi-Agyei, Y., Optimum use of biodegradable erosion control blankets and waste ballast (rock) mulch to aid grass establishment on steep slopes. J. Hydrologic Eng., 9(2), pp. 150-159, 2004a.

[3] Gyasi-Agyei, Y., Erosion risk assessment of controlled burning of grasses established on steep slopes, Journal of Hydrology, 317, 276-290, 2006.

[4] Gyasi-Agyei, Y., Pond water source for irrigation on steep slopes. J. Irrig. Drain. Eng., 129(3), pp. 184-193, 2003.

[5] Gyasi-Agyei, Y., Cost-effective temporary microirrigation system for grass establishment on environmentally sensitive steep slopes. J. Irrig. Drain. Eng., 130(3), pp. 218-226, 2004 b.

[6] Gyasi-Agyei, Y., Bhattarai, S., Fox, J. \& Nissen, D., Simultaneous multisite railway embankment steep slopes (batters) erosion control for a new spur line. Proc. of the $8^{\text {th }}$ International Conf. On Railway Engineering, ed. M.C. Forde, Engineering Technics Press, Edinburgh, pp. 1-10, 2005.

[7] Wu, I.P. \& Gitlin, H.M., Energy gradient line for drip irrigation laterals. $J$. Irrig. Drain. Eng., 101(4), pp. 323-326, 1975.

[8] Yildirim, G. \& Agiralioglu, N., Comparative Analysis of Hydraulic Calculation Methods in Design of Microirrigation Laterals. J. Irrig. Drain. Eng., 130(3), pp. 201-217, 2004.

[9] Hathoot, H. M., Al-Amoud, A. I. \& Mohammad, F. S., Analysis and design of trickle-irrigation laterals. J. Irrig. Drain. Eng., 119(5), pp. 756767, 1993.

[10] Kang, Y., \& Nishiyama, S., Analysis and design of microirrigation laterals. J. Irrig. Drain. Eng., 122(2), pp. 75-82, 1996.

[11] Vallesquino, P., \& Luque-Escamilla, P. L., Equivalent friction factor method for hydraulic calculation in irrigation laterals. J. Irrig. Drain. Eng., 128(5), pp. 278-286, 2002.

[12] Provenzano, G. \& Pumo, D. Experimental Analysis of Local Pressure Losses for microirrigation Laterals. J. Irrig. Drain. Eng., 130(4), pp. 318324, 2004. 
[13] Al Amoud, A. I., Significance of energy losses due to emitter connections in trickle irrigation lines. J. Agric. Eng. Res., 60(1), pp. 1-5, 1995.

[14] Gyasi-Agyei, Y., Field scale assessment of uncertainties in drip irrigation lateral parameters. J. Irrig. Drain. Eng., submitted. 